\title{
Article \\ A Crosslinguistic Study of Child Code-Switching within the Noun Phrase: A Usage-Based Perspective
}

\author{
Dorota Gaskins $^{1, * \mathbb{C}}$, Oksana Bailleul ${ }^{2}$, Anne Marie Werner ${ }^{3}$ and Antje Endesfelder Quick ${ }^{3}$ (D) \\ 1 School of Education, Communication \& Society, King's College London, London SE1 9NH, UK \\ 2 Department of Linguistics, Rouen Normandy University, 76130 Mont-Saint-Aignan, France; \\ oksana.bailleul@sorbonne-nouvelle.fr \\ 3 Institute of British Studies, Leipzig University, GWZ, Beethovenstraße 15, 04107 Leipzig, Germany; \\ werner_annemarie@hotmail.de (A.M.W.); antje.quick@uni-leipzig.de (A.E.Q.) \\ * Correspondence: dorota.gaskins@kcl.ac.uk
}

Citation: Gaskins, Dorota, Oksana Bailleul, Anne Marie Werner, and Antje Endesfelder Quick. 2021. A Crosslinguistic Study of Child Code-Switching within the Noun Phrase: A Usage-Based Perspective. Languages 6: 29. https://doi.org/ 10.3390/languages6010029

Received: 29 December 2020 Accepted: 8 February 2021 Published: 13 February 2021

Publisher's Note: MDPI stays neutral with regard to jurisdictional claims in published maps and institutional affiliations.

Copyright: (c) 2021 by the authors. Licensee MDPI, Basel, Switzerland. This article is an open access article distributed under the terms and conditions of the Creative Commons Attribution (CC BY) license (https:/ / creativecommons.org/licenses/by/ $4.0 /)$.

\begin{abstract}
This paper aims to investigate whether language use can account for the differences in code-switching within the article-noun phrase in children exposed to English and German, French and Russian, and English and Polish. It investigates two aspects of language use: equivalence and segmentation. Four children's speech is derived from corpora of naturalistic interactions recorded between the ages of two and three and used as a source of the children's article-noun phrases. We demonstrate that children's CS cannot be fully explained by structural equivalence in each two languages: there is CS in French-Russian although French does, and Russian does not, use articles. We also demonstrate that language pairs which use higher numbers of articles types, and therefore have more segmented article-noun phrases, are also more open to switching. Lastly, we show that longitudinal use of monolingual articles-noun phrases corresponds with the trends in the use of bilingual article-noun phrases. The German-English child only starts to mix English articles once they become more established in monolingual combinations while the French-Russian child ceases to mix French proto-articles with Russian nouns once target articles enter frequent use. These findings are discussed in the context of other studies which report code-switching across different language pairs.
\end{abstract}

Keywords: child code-switching; noun phrase; equivalence; segmentation

\section{Introduction}

Code-switching (CS) — the ability to shift seamlessly between one's two languagesis one of the most remarkable features of bilingualism, and especially striking when it comes from very young children. Children aged two to three, who are the focus of this study, are widely reported to use CS in their speech; they use more CS if it is modelled in parental input (Comeau et al. 2003), and when addressed in their weaker language which subsequently becomes the language they are expected to produce in interaction (Cantone and Müller 2005; Gaskins et al. 2019a). But children are still reported to switch even when their caregivers do not use bilingual utterances (Gaskins et al. 2019a; Mishina-Mori 2011), which suggests that CS is developmental. Some of it can be explained by more frequent use of the dominant language, which has implications for easier access to its words and constructions (Quick et al. 2019); some by the linguistic material being primed in the context of interaction (Quick et al. 2018a).

Most studies in child CS have examined it through a formalist lens. In the context of this framework, CS has been often referred to as a product of the asymmetry between the child's two emerging languages, justified by either lexical (Nicoladis and Secco 2000; Quay 1995) or structural gaps (Gawlitzek-Maiwald and Tracy 1996). Children may have a word for a given item in one language but not in the other, which explains switching to the former when naming that item. Likewise, children may not have a given morphosyntactic 
structure in one language and borrow it from the other language to satisfy a communicative need. The idea of CS as a result of an imbalance between the child's two languages is echoed in most research literature written to date, including two developmental accounts: the Bilingual Bootstrapping (Gawlitzek-Maiwald and Tracy 1996) and Ivy Hypothesis (Bernardini and Schlyter 2004).

Our study, however, explores CS from the perspective of usage-based (UB) theory, which sees it as an outcome of children's continuous experience with the languages they hear and use and their growing linguistic productivity. We are particularly interested in the impact of the child's own language production on the use of bilingual combinations; therefore, to eliminate the possibility that child CS may reflect CS in the input we only examine children who heard both of their two languages in one-parent-one-language (OPOL) scenarios. In our study we explore structural equivalence, which is seen as two languages expressing comparable concepts by means of phrases that use the same number of words, ordered in the same sequence (e.g., in referring to a dog, both English and German use noun phrases made up of pronominal articles and nouns, such as The dog in English and Der Hund in German). Children are reported to switch their two languages if both have equivalent constructions: for example, as both German and English use articles, there is CS in the German-English noun phrase, but as Russian does not, this explains lack of CS in young German-Russian bilinguals (Quick et al. 2016). In our study, such equivalence is examined as a factor emerging in development once the child has acquired corresponding constructions in both of their languages. We also explore the segmentation of constructions; matching chunks of phonology with chunks of semantic structure (e.g., a child might acquire the phrase $A$ dog holistically and segment it into two words $a$ and $d o g$ only upon using a range of similar constructions) (Dabrowska 2014). We speculate that monolingual constructions are acquired holistically and only become open to CS once they have become segmented in use.

In this paper, we take the view that language emerges from specific and concrete linguistic units whose representations are subsequently interconnected as a function of language usage depending on their patterns of co-occurrence, similarity, and domains of appropriate use (Wasserscheidt 2019). We argue that when this approach is used in cross-linguistic research, any comparisons should focus on a small set of specific, concrete, and comparable constructions. Therefore, we focus on article-noun phrases (ANPs) such as Der Hund 'the dog', which are present in the speech of all four children documented in this study. ANPs are also the most frequently occurring phrases with determiners in child language: in English, for example, they account for the total of $72 \%$ of all determiner tokens (Valian 1986). Our study adds to the debate as to what drives CS in the ANPs by bringing together naturalistic data from four two- to three-year-olds exposed to German-English, French- Russian and English-Polish respectively. We discuss how UB theory accounts for CS in these language pairs, which differ in terms of their levels of structural equivalence, morphological complexity, and phonological weight, and examine our findings in the context of other cross-linguistic research on the topic.

\subsection{Formalist Code-Switching Accounts}

Formalist accounts of child CS rely on an assumption of a dichotomous nature of the acquired language, where grammar and lexis are seen as separate (e.g., Bernardini and Schlyter 2004; Cantone 2007; Gawlitzek-Maiwald and Tracy 1996; Liceras et al. 2008; Myers-Scotton and Jake 2001; Petersen 1988). They are based on observations of regularities in language use across language communities, with the structure of language perceived as universal to mankind and triggered in a given linguistic environment, while lexis as emergent from sociolinguistic interaction. The concept of language structure being present at the onset of acquisition draws clear lines not only between the child's grammar and lexis but also between their two languages, conceptualising them as systems, or at least systems in the making, nevertheless two entities fairly separate from each other. The idea of linguistic uniformity has spurred a search for universal constraints which are understood 
to determine how children combine the grammars of their dominant (or matrix) language with lexical elements from the one which is weaker (see e.g., the Matrix Language Frame (MLF) model, Myers-Scotton and Jake 2001).

Most bilingual children are dominant in one of their two languages (Gathercole 2016; Paradis and Nicoladis 2007) and dominance does tend to determine the division of labour in mixed utterances (see Cantone (2007) for German-Italian; Deuchar and Quay (2000) for English-Spanish; Lanza (1997) for English-Norwegian). However, dominance of one language over the other cannot account for observations such that even within an individual child mixed utterances sometimes conform to a set of constraints and sometimes flout them (see Vihman (2018) for the discussion of the system morpheme principle and the morpheme order principle). In addition, dominance is unable to explain why within the same language pair children sometimes combine functional elements from the weaker language with lexical items from the stronger one (e.g., Müller et al. 2015). Under the MLF accounts, CS is also seen as a phenomenon which displays directionality, in that it is always one language that is mixed into another and not the other way round. This, in turn, makes them untestable, especially if the matrix language is accepted to change from one conversational turn to the next.

\subsection{Usage-Based Code-Switching Accounts}

Despite the capacity of the formalist models to account for many cross-linguistic patterns of CS, their limitations have spurred a search for alternative CS models. As a result, a novel account has been put forward derived from the cognitive framework of language usage (Tomasello 2003) which sees human cognition and its interaction with input as the main engines for the learning of both lexis and grammar. Specifically, the slot-andframe theory captures the longitudinal development of constructions which serve as a basis for the extraction of linguistic categories (Dabrowska and Lieven 2005; Lieven et al. 2009). Under this account, grammar is taken to emerge gradually from concrete lexical chunks and therefore the boundaries between lexis and grammar are seen as porous. For example, a construction Give me that may be produced as a frozen lexical chunk which has not yet been segmented and conceptualised as a combination of three different words. But it may also be produced as a partially schematic unit Give me $X$ where the words Give me are recalled as a frozen lexical chunk (henceforth referred to as 'frame') and combined creatively in online production with any item required in a given situation (henceforth referred to a 'slot filler'). Such use of partially schematic units is possible once Give me starts to be used with other words in the place of that.

The segmentation and subsequent productivity of this construction is frequencydriven and measured in terms of type-token ratios (TTRs): the more word types are used to fill the constructional slot (in place of that), the more segmented it becomes, supporting the emergence of a category of a certain word type which can be hosted within the construction (Bybee 2010). Once the category has emerged, the construction can be produced spontaneously in the moment of speech in a process akin to a 'beads-on-a-string assembly' (Walsh et al. 2010). For example, the child might request certain types of food, saying Give me cheese, based on her knowledge that in the construction Give me X, X can be filled with names for food types, and that cheese represents the category of food. Which part of the construction becomes the frame and which a slot is determined purely by their frequency of use: parts that have been used previously are considered to be frames while novel elements which are fixed to the new constructions are considered slot fillers (Dąbrowska and Lieven 2005).

The vast majority of spontaneously produced language can be explained by reference to language used in prior speech, be it in monolingual children or their bilingual peers. For example, among the first 400 multi-word constructions used by 11 monolingual toddlers aged 1;0-3;0 on average $60 \%$ are partially schematic units, including Put in $X, I$ want to $X$ and Go to X (Lieven et al. 1997). Data from monolingual two-year-olds video-recorded on a dense sampling schedule show that $78 \%-92 \%$ of utterances can be considered as 
combinations of frozen chunks and slot fillers, with most slots filled with nouns and noun phrases and increasing in complexity as a function of increasing mean length of utterance (MLU) (Lieven et al. 2009). As for bilingual children, Quick et al. (2018b) show that in the mixed utterances of a German-English speaking child aged 1;10-3;1, 61\% utterances belong to the category of partially schematic units. These results also hold for another German-English child and her English-Polish and English-Finnish peers: of all their mixed utterances studied, 63\%, 64\% and 61\% respectively are partially schematic units (Gaskins et al. 2019b). This demonstrates that bilingual speech is subject to the same processes of segmentation as that of monolingual children.

What motivates CS in such units? The openness of a construction to items from another language depends on how much the construction has been segmented in use. For example, once the child has realised that the phrase Give me cheese can be used to ask for things other than cheese, and developed a unit Give me X, the slot becomes open to elements from either language. The vast majority of CS can be explained by the creation of the constructional slot. A study of three two- to three-year-olds exposed to English-Polish, German-English, and English-Finnish reports that in $81 \%, 88 \%$ and $87 \%$ of all mixed utterances respectively the switch from one language to the other occurs between the monolingual frame from one language and the slot filler from another (Gaskins et al. 2019b).

Slot creation, however, cannot fully explain the construction's openness to material from another language: spontaneous speech of a Polish-English two-year-old shows that mixed constructions may have higher TTRs and be seen as more productive than their monolingual counterparts, but the switch placement can be better explained by examining the usage patterns of frames (Gaskins et al. 2019a). Constructions such as No X and More X, for example, seem to be open to CS because both no and more emerged as single words and became entrenched through autonomous use. Meanwhile, constructions such as The X and $M y X$ tend to be always monolingual because their frames emerged as, and continued to be used as, parts of constructions, with their structural and semantic identity reliant on the constructions they are part of (Gaskins et al. 2019a). This suggests that the constructional slots do not contribute to CS as much as the constructional frames.

In the constructions discussed in our paper, articles are taken as frames because they represent a closed-class category with low type-token ratios, often recycled in speech (Gaskins et al. 2019b; Quick et al. 2018b). Nouns are taken as slot fillers as they have the highest TTRs of all word types and their use is rarely restricted to specific constructions (Goodman et al. 2008). It is likely that segmentation of ANPs does result partly from high frequency of noun types occurring in the constructional slot (Bybee 2010). However, there is no reason to expect that children speaking different languages should exhibit different rates in their use of nouns. Therefore, we only test the hypothesis that such segmentation results from the usage of frames. Articles are never used autonomously, so we examine their productivity as linked to their TTRs: we speculate that ANPs in languages with higher numbers of article types become segmented, and open to CS sooner than ANPs in languages with lower numbers of article types. As different types, we consider both articles which are distinct (e.g., der and ein), and those which differ only in terms of their marking (e.g., der and den).

We also examine how segmentation interacts with structural equivalence. We speculate, for example, that the segmentation of English constructions is reinforced if English is acquired alongside German, but not Russian. If a child has constructions The dog and Der Hund, the awareness of the German construction being made up of two elements, and of the semantic correspondence between the English and German nouns, aids the segmentation of the English construction. This is not the case if English is acquired alongside Russian, as Russian does not use articles.

\subsection{Child Code-Switching within the Noun Phrase}

ANPs are the focus of this study because their use demonstrates considerable variation: in some languages, articles are readily combined with nouns or noun phrases 
from another language while in others they are not. No CS is reported, for example, in the acquisition of Polish and English (Gaskins et al. 2019a) or Russian and German (Quick et al. 2016). However, CS is reported widely across language pairs such as English and German (Jorschick et al. 2010; Quick et al. 2016), German and Italian (Cantone 2007), French and English (Swain 1972), as well as English and Spanish (Deuchar and Quay 2000; Liceras et al. 2008; Lindholm and Padilla 1978).

On the other hand, language pairs which license CS tend to show that mixed ANPs rely heavily on one of the children's languages as a source of determiners. Jorschick et al. (2010) show that in the CS between German and English the three children observed produced high numbers of mixed ANPs (296, 418 and 311). However, in all three children, regardless of their language dominance, the preferred pattern of switching was that of using a German article with an English noun (82\%, $n=242 ; 77 \%, n=321 ; 57 \%, n=178$ respectively). Data presented in Cantone (2007) study of four German and Italian children aged 1;7-2;4 also show high reliance on the German article das (as well as other function words such as dies, da, hier, ja, and nein) while Italian words most readily provide nouns but not articles in such combinations. This raises questions about why functional items (or in our nomenclature frames) are more readily derived from German than both English and Italian. Could this be in some way related to the complexity of German inflection (with definite and indefinite articles marked for case, number, and gender) which contrasts with both English (articles are only divided into definite and indefinite) and Italian (definite and indefinite articles marked for number, and gender)?

That ANPs depend on the more inflected language as a source of determiners becomes evident from other crosslinguistic research. In a case study of a child aged 2;10-6;2, French articles were used with English nouns (one definite and two indefinite) but none the other way round (Swain 1972). In a study of four Spanish and English children aged 2;10 6;2, children combined more readily Spanish articles with English nouns (seven definite and five indefinite) than English articles with Spanish nouns (three tokens) (Lindholm and Padilla 1978). This is reflected in the Spanish and English data from Deuchar and Quay (2000): the one child they studied between 0;11-1;8.24 was recorded using Spanish articles with English nouns (one definite and four indefinite) but did not combine a single English article with a Spanish noun. Dominance cannot account for the mixing patterns observed in these studies: the child discussed by Deuchar and Quay (2000) and the children observed by Lindholm and Padilla (1978), for example, were dominant in English and yet used Spanish articles with their English nouns. Liceras et al. (2008, p. 19) thus argue that children's reliance on articles from inflected languages is dictated by their need to "specify the uninterpretable features of articles from [inflected languages]". However, this explanation does not address (a) why there is altogether no CS in some language pairs and (b) why different studies of the same language pair report unidirectional (Deuchar and Quay 2000) while others bidirectional switching (Lindholm and Padilla 1978).

We want to approach these cross-linguistic results by referring to language usage, without evoking the child's recourse to the deeply embedded language representations. It has been previously argued, for example, that CS is facilitated by structural equivalence: if two languages are structurally similar, equivalence is likely to facilitate transitions between one language and the other (Quick et al. 2016). This could explain CS in German and English (Jorschick et al. 2010), Spanish and English (Lindholm and Padilla 1978), German and Italian (Cantone 2007), and French and English (Swain 1972) as all the languages mentioned here use ANPs. Likewise, this can explain lack of switching in Polish and English (Gaskins et al. 2019a) or Russian and German (Quick et al. 2016) as in each pair only one language uses ANPs.

Where the hereto mentioned studies do not support the equivalence accounts, a question should be asked about whether this could be due to the age at which children were studied. Is it possible that children simply do not have equivalent constructions at a certain age even though the two constructions are part of their two formal languages? Observations from the Spanish-English pair, for one, raise some suspicion that there may 
be some longitudinal change in the use of ANPs: there are no reports of switching English articles with Spanish nouns at the age of 0;11-1;8.24 (Deuchar and Quay 2000) but a few examples of such switches are reported at 2;10-6;2 (Lindholm and Padilla 1978). The role of the child's own language use in CS becomes even more transparent in the study of Jorschick et al. (2010): in the three children observed there were a few instances of the children combining English articles with German nouns (5\%, $n=15 ; 2 \%, n=8 ; 32 \%$, $n=98$ respectively), with the highest numbers recorded in the two children who had more exposure to English than German and who, as a result, had a higher mean utterance length (MLU) in English than in German. This again stresses the need to question the concept of equivalence and to investigate the ANP development longitudinally as a function of increased experience of language use.

The hint that language use plays a role in CS is supported further by the data from our own study of the acquisition of English and Polish: a child recorded between 0;9-2;5 used no combinations of English articles with Polish nouns despite the monolingual English ANPs being one of the most frequently produced combinations (Gaskins et al. 2019a). This observation is mirrored by the data from a Polish boy aged 6;2-7;7 learning English as a second language: not a single case of English articles mixed with Polish nouns is noted in his naturalistic recordings (Krupa-Kwiatkowska 1997). However, data from Ewert (1998) suggest that simultaneous bilinguals aged five do occasionally combine English articles with Polish nouns, suggesting that such switching might emerge with mounting exposure to the child's two languages. This raises questions whether structural equivalence might not be necessary for such switching to occur as long as the child has used their two languages sufficiently for the constructions to have been segmented in use.

Such segmentation is likely to occur in preschool years, with high variability but also some regularities observed in monolingual children studied across German, French, and English (Abu-Akel et al. 2004; Leroy-Collombel 2010; Szagun et al. 2007). German children start using both indefinite and definite articles before their second birthday, with a sharp increase in article use and misuse shortly after the age of two years and a drop in error rates to below 10\% just before their third birthday (Szagun et al. 2007). The third year of life experiences errors such as gender misassignment with nouns which do not conform to regularities, and overgeneralising to the frequent der instead of the less frequent die or das (Szagun et al. 2007) and their erroneous use may continue in the fourth year of life (Bittner 2006). In the acquisition of French, initially children reproduce whole ANPs without any errors, and it is only after their second birthday and once the concrete constructions have been analysed that gender errors begin to occur (e.g., le poule 'the hen' instead of la poule), leading gradually to the use of the relevant determiners with the right gender (Leroy-Collombel 2010). In the acquisition of English, children develop ANPs with the indefinite $a$ and the definite the before their second birthday and they continue to omit articles until the age of 36 months when most children supply close to $90 \%$ of articles in the required contexts (Abu-Akel et al. 2004). These studies show that while erroneous use of articles may continue beyond the age of three, the third year of life is particularly important to examine due to the shift in the number of errors made when using ANPs.

\subsection{Our Research Questions}

In the five languages studied here, only English, German, and French use articles (in all cases pre-nominally) while Russian and Polish do not. The three language pairs examined in this study have been chosen because they create a spectrum. In formal terms at least, the German-English pair offers a combination of two factors which could contribute to CS. First, German articles are expected to have high TTRs as German has definite and indefinite articles marked for gender, number, and case which could facilitate their early segmentation and their readiness to combine with a variety of nouns (see Table 1). Second, both German and English have equivalent ANPs (Der Hund 'the dog' and The dog) even though English definite and indefinite articles are uninflected. In the Russian-French pair only one of these factors is present. French articles are predicted to have relatively high 
TTRs: French uses definite and indefinite articles marked for gender and number, but Russian does not use equivalent ANPs (Le chien 'the dog' and Sobaka 'dog'). Lastly, in the Polish-English pair there are still fewer factors which could facilitate CS. English articles are expected to have low TTRs: there are definitive and indefinite articles, but they are uninflected which suggests that they may be structurally and semantically dependent on English nouns (Gaskins et al. 2019a). Also, Polish does not use equivalent ANPs (The dog and Pies ' $\operatorname{dog}^{\prime}$ ).

Table 1. Language pairs discussed in this study.

\begin{tabular}{|c|c|c|c|}
\hline & German-English & French-Russian & Polish-English \\
\hline equivalence & $\begin{array}{l}\text { German uses articles: } \\
\text { indefinite: ein, eine, einen, einem, einer, eines } \\
\text { definite: der, die, das, die, den, dem, des } \\
\text { English uses articles: } \\
\text { indefinite: } a \text {, an } \\
\text { definite: the }\end{array}$ & $\begin{array}{l}\text { French uses articles: } \\
\text { indefinite: } u n, \text { une } \\
\text { definite: } l e, l a, l e s, \\
\text { Russian uses none }\end{array}$ & $\begin{array}{l}\text { English uses articles } \\
\text { indefinite: } a \text {, an } \\
\text { definite: the } \\
\text { Polish uses none }\end{array}$ \\
\hline inflection & $\begin{array}{l}\text { German articles are inflected for gender, } \\
\text { number, and case } \\
\text { English articles are uninflected }\end{array}$ & $\begin{array}{l}\text { French articles are inflected } \\
\text { for gender and number }\end{array}$ & $\begin{array}{l}\text { English articles are } \\
\text { uninflected }\end{array}$ \\
\hline
\end{tabular}

The first research question we ask is how the bilingual children documented in this study use their ANPs in their third year of life. If structural equivalence is at play, at least in formal terms, we expect CS within German-English but not within French-Russian or English-Polish. This question is designed to highlight what types of switches are possible in different language combinations.

The second research question is whether the differences in the segmentation of frames can explain CS in ANPs, as reported in the results obtained for question 1. If segmentation is at play, we would expect high numbers of mixed ANPs in language pairs with high article type-token ratios. Contrarily, if there are any language pairs with no mixed ANPs, they should be the ones with low article type-token ratios.

The third research question is whether there is any longitudinal correspondence between the use of articles in monolingual and bilingual ANPs. If structural equivalence is at play, CS should only be possible when the child has developed equivalent ANPs in their two languages. If segmentation is at play, any increase in the use of articles in monolingual ANPs should also correspond with an increase in the use of such articles in mixed ANPs.

\section{Materials and Methods}

\subsection{Participants}

\subsubsection{German-English}

Sylvie was born in a mid-sized city in Germany at full-term and was a normally developing child. Throughout the study she remained the only child, she continued to live in Germany and to hear English from her mother and German from her father. Even though her parents interacted in German, as the father did not speak English, in their interactions with Sylvie they adhered to the one-parent-one-language (OPOL) strategy. In the first 18 months of her life, Sylvie stayed at home with her mother who was the only person to address her in English but then she started attending a German kindergarten for 45 hours per week. At the data sampling period (2;4-2;11), Sylvie was dominant in German: her German MLU was 5.36 (2;11) and her English MLU was 3.2 (2;11).

\subsubsection{French-Russian}

Camille was born in a large city of France at full term and was a normally developing child. The family lived in France and the child heard two languages from her birth on a daily basis: Russian from her mother while French from her father and other French family members (grandparents, aunts, and uncles). The child stayed at home with her mother till 
the age of $1 ; 0$ and then with her French grandmother till the age of 2;4. Camille attended French childcare from 2;4 to 3;0 (20 hours per week). The parents spoke French with each other. They adopted OPOL with the child, but the mother sometimes switched to French. During the recording period $(2,1-3 ; 0)$ Camille was dominant in French: her French MLU was 3.5 (3;0) whilst her Russian MLU was $2(3 ; 0)$.

\subsubsection{Polish-English}

At the data sampling period Sadie was an only child, born in a large city in the UK at full term and developing normally. She heard Polish from the day she was born from her mother only, and sometimes from her visiting maternal grandmother, while English was the language of her daily environment, her father, her peers, and her nursery staff. In this sense, her two languages were delivered to her separately, with minimal evidence of CS in the input (see also Gaskins et al. 2019a). At the age of one, Sadie started to attend an English-speaking nursery three days a week, ten hours a day. She was dominant in English, with her English MLU at 2.35 (2;05.11) and her Polish MLU at 1.0 (2;04.15).

Tessa was Sadie's younger sister and her language constellation mirrored that of her sister except she also heard English from an older sibling on a daily basis at home. This was not the case with Polish: Tessa was born when Sadie was three-and-a-half years old and when she went through a phase of refusing to speak any Polish. Tessa was also dominant in English, with her English MLU at 3.62 (2;09.15) while her Polish MLU at 1.45 (2;09.15).

\subsection{Data}

\subsubsection{German-English}

There are 16 recordings available in Sylvie's linguistic corpus: two one-hour recordings per month between the ages of 2;04 and 2;11. The recordings were made in the presence of both parents, during mealtimes and playtimes. They were transcribed and coded by a research assistant. There was no evidence of mixed ANPs in parental input.

\subsubsection{French-Russian}

There are 12 recordings available in Camille's corpus, totalling $30 \mathrm{~min}$ per month (2;1-3). They were made once a month during interactions between the child and her Russian-speaking mother, and sometimes also the child's French-speaking father or her French-speaking grandmother. The child was recorded during such activities as reading books, talking about picture books, playing Lego, clay modelling and role-play. The interactions were transcribed by the child's mother, the second author of this article. Only one mixed ANP was recorded in parental input.

\subsubsection{Polish-English}

There are 30 half-hour video recordings $(1 ; 10.16-2 ; 5.11)$ available in Sadie's corpus. Data from Sadie's corpus cover a slightly younger age bracket than those of her peers. However, the decision to include the earliest recordings is justified by the observation that Sadie had developed noun phrases in time for the first recording (Gaskins et al. 2019b). These recordings were made on average every 4-7 days, with either Sadie's Polish-speaking mother $(n=10)$, her English-speaking father $(n=10)$ or sometimes both parents present at the table $(n=10)$. During the interactions, Sadie was given a meal and she was subsequently involved in looking at books, matching up animal cards and playing Lego. Her data were transcribed and coded by her mother, the first author of this article. As Sadie's data were available only until 2;5.11, her sister's data were used in a supporting role to validate the patterns for the language pair and to examine whether they changed closer to the third birthday.

Tessa's language use was documented through 10 monthly half-hour interactions recorded on video under conditions comparable to those of her sister (2;00.01-2;09.15). These are the only recordings available for the child and they all feature interactions in 
Polish with Tessa's Polish-speaking mother who also transcribed and coded all language use. No mixed ANPs were recorded in Sadie or Tessa's input.

\subsection{Summary of Differences}

Although the four children observed in this study are comparable in terms of their age of exposure to both languages, the language policy followed at home, the place of recording, and their dominance in the community language, admittedly their data do capture slightly different developmental stages and are made at different intervals (Table 2). Differences are also evident in the type and number of speakers present with the children in the process of recording: Sylvie was always recorded when addressed in both of her languages, Camille and Sadie were sometimes recorded in monolingual and sometimes in bilingual contexts while Tessa's speech was only ever captured on video when she was addressed in Polish. Last but not least, children's proficiency in each of their two languages differed considerably, with Tessa displaying the largest gap in the proficiency between her stronger and weaker language (3.62 vs. 1.45), as measured by her MLUs, followed by Sylvie (5.36 and 3.2), Camille (3.5 vs. 2) and then Sadie (2.35 vs. 1).

Table 2. The summary of differences between the datasets.

\begin{tabular}{ccc}
\hline & Total Recording Length & Total Monolingual and Bilingual ANPs \\
\hline Sylvie & $22 \mathrm{~h}$ & 371 \\
Camille & $6 \mathrm{~h}$ & 193 \\
Sadie & $15 \mathrm{~h}$ & 127 \\
Tessa & $5 \mathrm{~h}$ & 40 \\
\hline
\end{tabular}

Admittedly, the children's CS rates may have been influenced (a) by the number of languages each child heard during the recordings, (b) by the differences in the proficiency between each child's two languages, and (c) by the different activities children did while being recorded; therefore, these factors need to be considered in the discussion. While it is important to compare initially the CS rates in all children studied, the main aim of this study is to examine the qualitative aspects of CS in these children which, in turn, backgrounds the initial focus on its quantitative aspects. Meanwhile, it is also important to remind the reader that this study is based only on four children across three language pairs and therefore any similarities and differences between the datasets need to be interpreted with caution.

\subsection{Data Analysis}

To address question one about how the four children used ANPs in the three language pairs, we isolated all monolingual and bilingual ANPs from the child speech.

To address question two about the extent to which frame segmentation facilitates the children's CS, construction productivity was calculated on the basis of the monolingual usage of these constructions. As the datasets differed in terms of size, in our calculations, we used standardised type-token ratios (STTRs) (Scott 2004; Malvern and Richards 2002): we divided all ANPs into sets of 100, calculated the TTR for the frames in each set and took the mean value of the TTRs; the last set, which was shorter than the standard-size sets, was excluded from analysis. We obtained three sets from Sylvie's data, but only one for Camille and Sadie. Tessa's ANPs were excluded from analysis due to small numbers $(n=40)$. However, it is important to note that Tessa used articles $a$ and the throughout the data recording period, and started using an at 2;3, which suggests that the productivity of her frames was similar to that of Sadie's.

To address question three, the children's ANPs were examined longitudinally, with intervals determined by the data sampling points. Mixed ANPs were isolated from monolingual ANPs and illustrated in separate bar charts. This was to examine the age at which articles emerged in monolingual use, the age at which they started to be used more frequently in 
monolingual constructions and to determine whether either of these corresponded with the onset of CS within these combinations.

\section{Results}

\subsection{The Use of ANPs in the Three Language Pairs}

The first step of analysis isolated all ANPs from the child speech (Table 3). The data show that there were mixed ANPs in the speech of the children acquiring German and English, and French and Russian but not in those acquiring English and Polish.

Table 3. The total numbers of ANPs in child naturalistic speech.

\begin{tabular}{ccccccc}
\hline Sylvie & mixed & $70(19 \%)$ & German & 236 & English & 65 \\
\hline Camille & mixed & $8(4 \%)$ & French & 185 & Russian & 0 \\
\hline Sadie & mixed & 0 & English & 127 & Polish & 0 \\
\hline Tessa & mixed & 0 & English & 40 & Polish & 0 \\
\hline
\end{tabular}

\subsection{The Segmentation of ANPS in Child Speech}

The second step of analysis focused on establishing productivity of constructions to explain their openness to CS (Table 4). Our data show that across the four children studied, the most productive ANPs were found in the German-English data. In fact, throughout the data sampling period the numbers of German articles used were high (with 8 being the lowest and 10 the highest count of article types per each ANP segment). The second most productive frame was recorded in the acquisition of French and Russian. It was calculated out of all the target articles used, excluding the proto determiners $i$ and $a$, whose use compared respectively though not systematically with the definite le/la and the indefinite un/une (Bailleul 2017). Lastly, the productivity of frames in Sadie's ANPs was the lowest in the whole group.

Table 4. The productivity of frames across the ANPs produced by the children.

\begin{tabular}{cccc}
\hline & German-English & French-Russian & English-Polish \\
\hline STTR & 0.09 & 0.07 & 0.03 \\
\hline
\end{tabular}

\subsection{The Longitudinal Change in the Use of ANPS}

The third step of analysis focused on examining the longitudinal change in the children's use of ANPs. Our results show that in the bilingual acquisition of German and English the use of all German articles in monolingual German constructions was established from the beginning of, and throughout, the data sampling period in that the child used German articles in every single recording (see Figure 1B). This may explain their use in mixed constructions with English nouns (Figure 1A). On the other hand, the use of English articles was not established as in some recordings it was completely absent from monolingual English speech (see Figure 1C) and their frequency increased only in the last three months of the study, which coincides with the onset of their use in mixed utterances (Figure 1A).

Our results for the bilingual acquisition of French and Russian are presented in Figure 2. Figure 2A shows that the overall use of French ANPs was lower before than after the age of 2;7, when it suddenly increased in frequency. Furthermore, Figure $2 \mathrm{~B}$ shows that proto-determiners were only used up to the age of 2;7 when they fell out of use. 


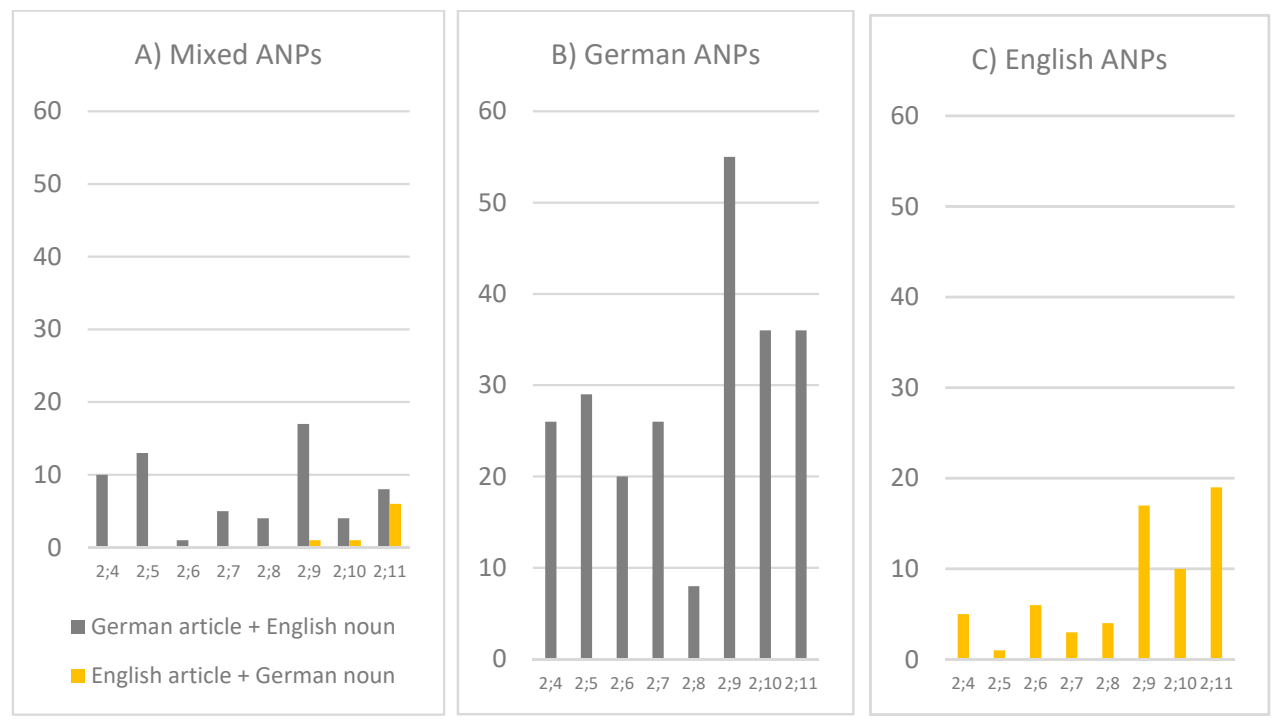

Figure 1. Frequency of use of ANPs in German-English, according to age.
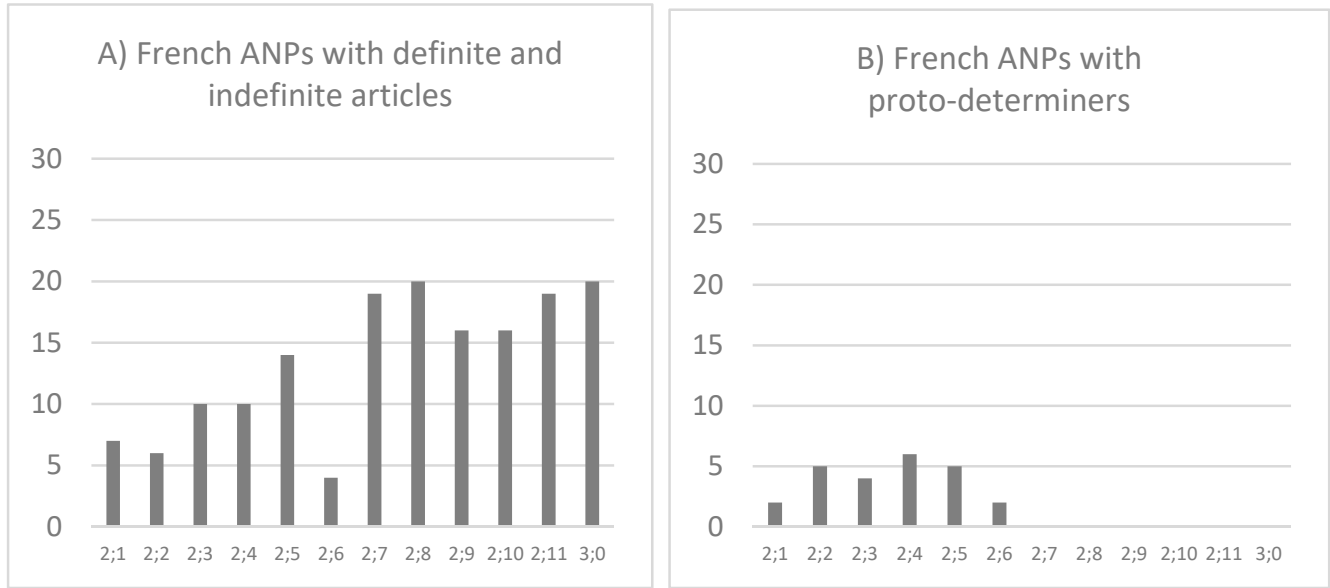

Figure 2. Frequency of use of ANPs in French-Russian, according to age.

How does the use of French articles in monolingual speech correspond with their use in mixed combinations? There were several examples of Russian nouns combined with French proto-determiners (Figure 3A), a usage pattern which corresponds (a) with the mere presence of proto-determiners in monolingual French ANPs (Figure 2B) and (b) with the infrequent use of target-like articles until the age of 2;7 (Figure 2A).

The mixed ANPs feature three combinations with the syllable $i$ (e.g., là $i$ kamouchek $(2 ; 2)$ 'there (a) stone') and three combinations with the syllable $a$ (e.g., a koukla $(2 ; 5)$ '(a) doll'). By comparison, there were 24 tokens of monolingual ANPs with proto-determiners (e.g., i fleure (2;1) 'a flower' and sur a chaise? $(2 ; 5)$ 'on (the) chair?'). Thus, here CS occurred in phrases which the child produced en route to more target-like constructions.

Age 2;7 saw a significant change in the use of ANPs: articles started being used more frequently and proto-determiners were filtered out of use, both from mono- and bilingual ANPs. There were also two instances of indefinite French articles mixed with Russian nouns such as un sova 'an owl' (2;5) and une krabik 'a crab' (3;0) (Figure 3B). This shows that, contrary to equivalence accounts, such combinations are possible in the acquisition of French and Russian, albeit rare. 


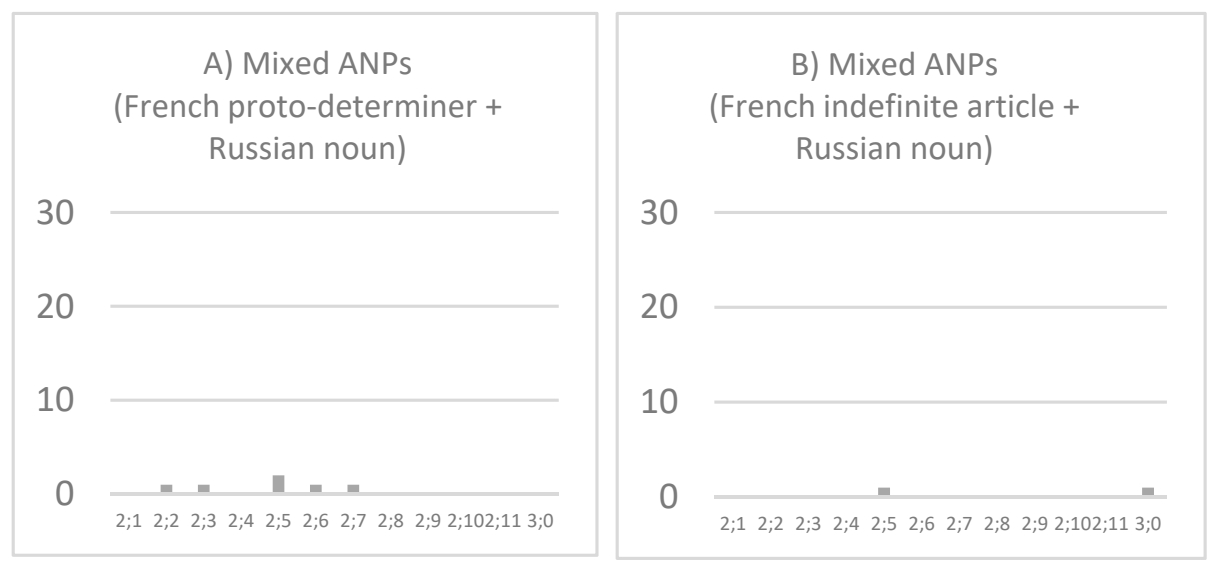

Figure 3. Frequency of use of mixed ANPs in French-Russian, according to age.

\section{Discussion}

This study examined CS within the ANPs in four two- to three-year-old children exposed to German-English, French-Russian and Polish-English. To address question one about how ANPs are used between the ages of two and three, we isolated all bilingual ANPs from the children's speech. This allowed us to show that there is CS within this construction in the acquisition of German and English, and French and Russian but not in the acquisition of English and Polish, at least in the two children we studied and at least up to their third birthday. The patterns observed in the German-English and English- Polish pairs support the equivalence accounts (Quick et al. 2016): there is structural equivalence in the former, which can explain CS, but no equivalence in the latter, which can also explain the absence of CS. However, our findings from the French-Russian pair suggest that equivalence alone cannot fully explain why CS occurs because Camille did use mixed ANPs both with proto-determiners and with French indefinite articles.

To address question two and to determine whether the segmentation of constructions may explain CS in ANPs, we examined productivity of the constructional frames. Our findings show that the frames in the acquisition of German and English ANPs were the most segmented of all language pairs (0.09), and this was for at least two reasons. First, German articles are inflected and, compared to the other languages examined in this study, in Sylvie's speech a range of articles emerged early on, meaning that throughout the data sampling period the numbers of German articles used were high. Second, English articles were being acquired alongside their German counterparts which boosted the numbers of article types used. The second highest TTR was that recorded in French and Russian (0.07), while the lowest that recorded in English and Polish (0.03). This partly supports the findings from Gaskins et al. (2019a) that frame productivity plays a role in child CS: switching in the data from German and English, and French and Russian can be linked to the productivity in Sylvie's and Camille's ANP frames. Also, the lack of CS within the ANP in the data from English and Polish can be explained by the fact that only three articles were used as Sadie's monolingual ANP frames. However, the difference in STTRs between German-English (0.09) and French-Russian (0.07) is perhaps not sufficient to warrant a correspondence between the extent of construction segmentation and the differences in CS rates-a difference apparent even if the difference in recording length is taken into account. It thus seems more reasonable to assume that the segmentation effect adds to the equivalence effect: that frequently mixed ANPs in English-German are a function of both factors and that lower mixing rates in the French-Russian ANPs are the result of just one factor.

Referring back to the UB theory can help us to explain these cross-linguistic differences. According to earlier CS research, mixed ANPs can arise via the frame in one language hosting a noun in the other (Gaskins et al. 2019b). In bilingual acquisition, this shows at most two possible routes to creating mixed ANPs. In the case of English and German, 
for example, there is structural equivalence in the use of ANPs and therefore, both routes are possible: a German frame can be combined with an English noun (e.g., Der dog) or an English article can be combined with a German noun (e.g., The Hund). In the process of bilingual acquisition of these two languages, a child develops progressively more abstract schemas (e.g., German article + German noun $\rightarrow$ German article X, English article + English noun $\rightarrow$ English article X); as they become abstract, they also eventually become completely segmented in use and thus open to hosting items from either language, leading to frequent CS. Thus, in the case of German and English, CS appears to be facilitated by both structural equivalence and frame segmentation. In the process of bilingual acquisition of French and Russian, this is however not the case. The child can only develop an abstract schema in French (e.g., French article + French noun $\rightarrow$ French article X) but not in Russian, as Russian does not use articles. Therefore, CS can only occur via one route-when Russian nouns are hosted is the slots of French ANPs, which presumably becomes possible only when the French frame becomes segmented in use. Thus, here the presence of one factorsegmentation-but the absence of equivalence may explain the near absence of CS within French-Russian ANPs, compared to their German-English counterparts. Meanwhile, as Polish language does not use articles, such abstract schema cannot arise in Polish and there is only one potential route to creating mixed English-Polish ANPs-through an English schema hosting Polish nouns. At the age of three, however, the English ANPs do not appear to be segmented enough to facilitate such CS and it only becomes possible later in acquisition, although it is rare (Ewert 1998). Therefore, the absence of mixing in these children acquiring Polish-English could be linked to the absence of both factors: equivalence and segmentation.

Our study also shows that English articles enter in combination with German but not with Polish nouns. Does this mean that the frame within ANPs becomes segmented when English is acquired in conjunction with German but not in conjunction with Polish? We speculate that frame segmentation may be delayed in cases where there is no structural equivalence between the two languages because there is no reinforcement in the segmentation of the ANP in one language by that of an equivalent ANP in the other. In bilingual speakers, one language is never completely inhibited while the other is in use which allows children to make constant comparisons between their two languages (Grosjean 2008). In the case of ANPs, Sylvie's knowledge of German articles is likely to reinforce her understanding of what English articles are used for and this, in turn, will facilitate the segmentation of English articles in speech. On the other hand, Sadie and Tessa's segmentation of English articles relies solely on the use of English articles, without an option of making comparisons with Polish language.

The segmentation of the constructional frames is likely to be additionally facilitated in German by what we refer to as phonological weight. Articles which are perceptually salient, as is the case with German but not so much with English articles, are likely to stand out more in the context and to be more easily distinguishable from each other. As a start, the most basic German articles contain rhotic /r/ in der and sibilant /s/ in das which are likely to add to their phonological weight in the context. By contrast, English articles are hardly ever stressed and therefore they are not fully articulated: the indefinite article is most commonly realised as a short unstressed $/ \partial /$ and the definite article as a short unstressed $/ \Theta \ni /$, meaning that they may not be clearly heard. This lack of phonological weight is likely to take away from the child's awareness that an English article is a separate word which can be combined creatively with others in spontaneous use. Segmentation may also be facilitated by a series of other factors whose examination fell outside the scope of this study due to its narrow focus on the ANPs. Among them are the use of other noun phrases and any potential similarities observed with those.

To address question three about any correspondence between the longitudinal development of ANPs in monolingual speech and the CS patterns, we examined the speech of the two children who used mixed ANPs, one child acquiring German and English and one acquiring French and Russian. Our results provide further evidence that CS can be 
explained by the segmentation of frames in use. In the acquisition of German and English, the numbers of mixed ANPs can be linked with their use in monolingual speech: (a) the regular use of German articles already at the age of 2;4 explains their readiness to combine with both German and English nouns while (b) the infrequent use of English articles up to the age of 2;8 explains the fact that they do not combine with German nouns. In fact, it is only when English articles start being used more frequently at the age of 2;9 that they start to enter in combination with German nouns. Our observation of a reliance on inflected German articles in mixed ANPs mirrors the results from previous research (Jorschick et al. 2010) but it additionally suggests the reason behind this asymmetry in switching. We argue that the preference for using articles from inflected languages in combination with nouns from uninflected languages may not necessarily be motivated by what Liceras et al. (2008, p. 19) call the need to "specify the uninterpretable features of [inflected languages]". Instead, we believe it can be explained by the enhanced segmentation of the constructional frames in the inflected language through children's early experience of multiple article use. Such segmentation could certainly explain the asymmetry between German and Italian (Cantone 2007), French and English (Swain 1972) and Spanish and English (Lindholm and Padilla 1978; Liceras et al. 2008). In each case mentioned here the former language offers higher numbers of article types than the latter, meaning that frames in the former are more likely to be segmented early in acquisition and ready to combine with nouns from the latter, leading to the reported asymmetry in CS.

Such segmentation could also explain why different studies in acquisition of Spanish and English report unidirectional while others bidirectional switching. Deuchar and Quay (2000), for example, report reliance on Spanish determiners with English nouns between the ages of $0 ; 11-1 ; 8.24$, a pattern reflected by our early data from Sylvie's productions in English and German. Meanwhile, Lindholm and Padilla (1978) show bidirectional CS in Spanish and English between the ages of 2;10-6;2, reflected by Sylvie's productions from the age of 2;9 onwards. If we take segmentation to be responsible for the shift in English-German CS, it might also be able to explain the data from Spanish-English.

Our results from the acquisition of French and Russian do not however correspond with those from the German and English pair. The infrequent use of French articles up to the age 2;7, intertwined with the use of proto-determiners, may explain the readiness of French proto-determiners to combine with Russian nouns. It is possible that the use of French articles in combination with Russian nouns reflects the child's lack of awareness of how articles are used, and that it marks a phase when the child is trying to figure out the rules for article usage. This interpretation of our data would correspond with what is known about the acquisition of French ANPs: that article misassignment only starts to occur after concrete constructions have been analysed and thus it marks a phase when children start to figure out combinatorial rules (Leroy-Collombel 2010).

Overall, the data from the acquisition of French and Russian call into question the need for children to use articles from inflected languages to specify uninterpretable features in uninflected languages (Liceras et al. 2008). If that view was correct, there would be no reason for a change in the CS rates. However, in Camille's case, there is a drop in the CS of French proto-determiners with Russian nouns, suggesting a developmental factor is at play. The view promoted by Liceras et al. (2008) is also challenged by the lack of CS in both Sadie's and Tessa's ANPs as in our data no English articles were used with Polish nouns. Ideally, the results from our study should be compared with other longitudinal studies in French and Russian CS. However, this is not possible as, to the best of our knowledge, such studies do not exist. Absent from the research literature are also studies of child CS in French and other Slavic languages which could potentially contribute to the debate. The only data which can add to our discussion come from the experimental study of children aged 3;6-5;6 who spoke German and Russian (Quick et al. 2016). Like French, German uses articles, while Russian does not, thus creating a pair without structural equivalence. The researchers did not capture any CS within the German-Russian ANPs but this may have been due to the fact that the experiment was less likely to capture the single instances of 
CS which were recorded in our naturalistic French-Russian corpus. It may have also been due to the fact that the children's speech was sampled only at one point in time or that it was sampled after the age of three when children gradually stop making errors in their use of articles. Therefore, an in-depth explanation of our findings from the acquisition of French and Russian is missing here and this remains a limitation of our study.

Overall, however, the UB approach seems a better fit for our data than the formalist models. First, language dominance, at least measured as dominance of one whole language over the other, would not be able to account for all the CS recorded in our study (Bernardini and Schlyter 2004; Myers-Scotton and Jake 2001; Petersen 1988). If the dominance accounts were accurate, the children discussed in this study who were dominant in German, French, and English respectively should have been able to use German, French and English articles with English, Russian and Polish nouns. But this kind of CS is only evident in the first two pairs. In particular, Tessa should have had the most mixed ANPs as there is the greatest gap in her proficiency in English and in Polish, but this was not the case. Similarly, dominance can explain Sylvie's mixing of German articles with English nouns but not vice versa. Dominance also does not seem sufficient in explaining why Camille mixed her proto-articles from French into Russian but her target-like French articles did not readily combine with her Russian nouns. Clearly, the latter observation needs to be explained when examined through the lens of a more dynamic framework. Second, our data call into question the need for recording CS in highly controlled sociolinguistic contexts. Sadie's speech was examined in three different scenarios, but her English articles did not combine with Polish nouns either in bilingual contexts, which could have encouraged language interaction, or when she was addressed in English, which could have triggered the transfer of an English article into constructions with Polish nouns. Likewise, Tessa was recorded when addressed in her weaker language, that which typically encourages the most CS, and yet no interaction was recorded within her ANPs. This tells us that CS cannot be down to the context of interaction, but it must have something to do with the two languages spoken by the girls, and we argue that the segmentation of equivalent constructions in both languages offers an important lens for studying the interaction between their developing structures.

Meanwhile, we would like to stress that the theoretical potential of the empirical data presented in this paper should not be overstated given the fact that only one child per language pair was studied, and that there are quite some differences between the children and the way their data was collected. The small number of children studied remains the main limitation of this study, and one which should be addressed through further research. Future studies comparing children across language pairs should control for a wide array of confounding factors which may affect the numbers of mixed utterances produced. Our study did control for some of such factors but there are many others which have made it difficult to tease apart development and cross-linguistic differences. For example, while all children were recorded at home, during mealtimes and playtimes, it is possible that the type of activities they did while being recorded affected the amount of their language interaction. Also, if Sadie had been recorded until the age of three, like Sylvie and Camille, we might have captured some mixed ANPs in her speech. It is also likely that if Camille had been recorded more frequently, her recordings would have captured more instances of mixed ANPs.

On one last note, we would like to stress that this study does not compare CS between three languages pairs, but merely between four individual children exposed to these language pairs, who did not hear CS in their input. Such an approach allows us to limit our findings to particular individuals while allowing for the possibility that they do not hold for other children exposed to the same language pairs. We acknowledge that CS is induced by many factors alongside equivalence and segmentation, and that all these factors interact differently for each and every single child observed. For one, we envisage that some preschool children exposed to Polish and English may use mixed ANPs if these are 
heard in their input and offer them some ready-made bilingual chunks for mere recycling. This is one other avenue to explore in research on CS in Polish-English pre-schoolers.

\section{Conclusions}

Our analysis of the bilingual conversational data of children acquiring German and English, French, and Russian as well as English and Polish shows cross-linguistic variation in the employment of mixed ANPs, at least in the children studied and at least up to the age of three. We demonstrated that the differences in the individual patterns of usage are shaped by (a) the frequency-driven segmentation of frames in the monolingual constructions and (b) the use of equivalent constructions in both of the child's languages. We also acknowledged a range of additional factors which may have affected our results. Our discussion of other studies of CS within the ANP allowed us to place our findings in the context of other studies on mixing within the noun phrase, and to formulate a UB explanation for the patterns observed cross-linguistically.

Author Contributions: Conceptualization, D.G. and A.E.Q.; methodology, D.G. and A.E.Q.; formal analysis, D.G., O.B. and A.E.Q. data curation, D.G., O.B., A.M.W. and A.E.Q.; writing-original draft preparation, D.G.; writing-review and editing, D.G.; visualization, D.G. All authors have read and agreed to the published version of the manuscript.

Funding: This research received no external funding.

Institutional Review Board Statement: The study with Polish-English children was conducted in accordance with the Declaration of Helsinki, and the protocol was approved by the School of Sciences, History and Philosophy Ethics Committee at the University of London (code 2012-09). Ethical review and approval were waived for the study with German-English and French-Russian children, as German and French universities do not require approval for this type of research.

Informed Consent Statement: Informed consent was obtained from all subjects involved in the study.

Data Availability Statement: The French-Russian data discussed here available from the CHILDES Database. Data for the other three children are available from the corresponding author upon request.

Acknowledgments: Our sincere thanks to the editors of this issue as well as the anonymous referees, whose comments helped to improve the paper. All the remaining weaknesses are our own.

Conflicts of Interest: The authors declare no conflict of interest.

\section{References}

Abu-Akel, Ahmad, Alison Bailey, and Yeow-Meng Thum. 2004. Describing the Acquisition of Determiners in English: A Growth Modeling Approach. Journal of Psycholinguistic Research 33: 407-24. [CrossRef]

Bailleul, Oksana. 2017. Aspects psycholinguistiques du développement du bilinguisme précoce: une étude de cas d'un enfant bilingue français-russe de 2 à 4 ans. Ph.D. dissertation, University of Rouen, Rouen, France.

Bernardini, Petra, and Suzanne Schlyter. 2004. Growing syntactic structure and code-mixing in the weaker language: The Ivy Hypothesis. Bilingualism: Language and Cognition 7: 49-69. [CrossRef]

Bittner, Dagmar. 2006. Case before Gender in the Acquisition of German. Folia Linguistica XL: 115-34. [CrossRef]

Bybee, Joanne. 2010. Language, Usage and Cognition. Cambridge: CUP.

Cantone, Katja Francesca. 2007. Code-Switching in Bilingual Children. Dordrecht: Springer.

Cantone, Katja Francesca, and Natascha Müller. 2005. Code-switching at the Interface of Language-Specific Lexicons and the Computational System. International Journal of Bilingualism 8: 205-25. [CrossRef]

Comeau, Liane, Fred Genesee, and Lyndsay Lapaquette. 2003. The modelling hypothesis and child bilingual codeswitching. International Journal of Bilingualism 7: 113-26. [CrossRef]

Dabrowska, Ewa. 2014. Recycling utterances: A speaker's guide to sentence processing. Cognitive Linguistics 25: 617-53. [CrossRef]

Dabrowska, Ewa, and Elena Lieven. 2005. Towards a lexically specific grammar of children's question constructions. Cognitive Linguistics 16: 437-74. [CrossRef]

Deuchar, Margaret, and Suzanne Quay. 2000. Bilingual Acquisition. Theoretical Implications of a Case Study. New York: OUP.

Ewert, Anna. 1998. Memory in a child's foreign language acquisition. In Studies in Foreign Language Learning and Teaching. Prace naukowe Uniwersytetu Ślaskiego nr 1666. Edited by J. Arabski. Katowice: Wydawnictwo Uniwersytetu Śląskiego, pp. 11-20. 
Gaskins, Dorota, Ad Backus, and Antje Endesfelder Quick. 2019a. Slot-and-frame schemas in the language of a Polish- and Englishspeaking child: The impact of usage patterns on the switch placement. Languages 4: 8. [CrossRef]

Gaskins, Dorota, Maria Frick, Elina Palola, and Antje Endesfelder Quick. 2019b. Towards a usage-based model of early code-switching: evidence from three language pairs. Applied Linguistics Review. [CrossRef]

Gathercole, Virginia. 2016. Seven factors moderating proficiency in bilingual speakers. In Bilingualism across the Lifespan: Factors Moderating Language Proficiency. Edited by Elena Nicoladis and Simona Montanari. Washington, DC: Walter de Gruyter and American Psychological Association, pp. 123-40.

Gawlitzek-Maiwald, Ira, and Rosemarie Tracy. 1996. Bilingual Bootstrapping. Linguistics 34: 901-26. [CrossRef]

Goodman, Judith, Philip Dale, and Ping Li. 2008. Does frequency count? Parental input and the acquisition of vocabulary. Journal of Child Language 35: 515-31. [CrossRef] [PubMed]

Grosjean, Francois. 2008. Studying Bilinguals. Oxford: OUP.

Jorschick, Liane Antje Endesfelder Quick, Dana Gläser, Elena Lieven, and Michael Tomasello. 2010. German-English-speaking children's mixed NPs with 'correct' agreement. Bilingualism: Language and Cognition 13: 1-11. [CrossRef]

Krupa-Kwiatkowska, Magda. 1997. Second-language acquisition in the context of socialization: A case study of a Polish boy learning English. Unpublished dissertation, State University of New York at Buffalo, Buffalo, NY, USA.

Lanza, Elizabeth. 1997. Language Mixing in Infant Bilingualism. A Sociolinguistic Perspective. Oxford: Oxford University Press.

Leroy-Collombel, Marie. 2010. Eveil de la conscience grammaticale chez un enfant français entre 18 mois et 3 ans. In Congres Mondial de Linguistique Francaise - CMLF. Edited by Francois Neveu, Valelia Muni Toke, Jacques Durand, Thomas Klingler, Lorenza Mondada and Sophie Prévost. Les Ulis: EDP Sciences.

Liceras, Juana. M., Raquel Fernández Fuertes, Susana Perales, Rocio Pérez-Tattam, and Kenton Todd Spradlin. 2008. Gender and gender agreement in bilingual native and non-native grammars: A view from child and adult functional-lexical switchings. Lingua 118: 827-51. [CrossRef]

Lieven, Elena, Julian Pine, and Gillian Baldwin. 1997. Lexically-based learning and early grammatical development. Journal of Child Language 24: 187-220. [CrossRef]

Lieven, Elena, DorothèSalomo, and Michael Tomasello. 2009. Two-year-old children's production of multiword utterances: A usage-based analysis. Cognitive Linguistics 20: 481-507. [CrossRef]

Lindholm, Kathryn, and Amado Padilla. 1978. Language switching in bilingual children. Journal of Child Language 5: 327-35. [CrossRef]

Malvern, David, and Brian James Richards. 2002. Investing accommodation in language proficiency interviews using a new measure of lexical diversity. Language Testing 19: 85-104. [CrossRef]

Mishina-Mori, Satomi. 2011. A longitudinal analysis of language choice in bilingual children: the role of parental input and interaction. Journal of Pragmatics 43: 3122-38. [CrossRef]

Müller, Natascha, Laia Arnaus Gil, Nadine Eichler, Jasmin Geveler, Malin Hager, Veronika Jansen, Marisa Patuto, Valentina Repetto, and Anika Schmeißer. 2015. Code-Switching: Spanisch, Italienisch, Franzosisch. Eine Einfuhrung. Tübingen: Narr.

Myers-Scotton, Carol, and Janice Jake. 2001. Explaining aspects of code-switching and their implications. In One Mind, Two Languages: Bilingual Language Processing. Edited by Janet Nicol. Malden: Blackwell Publishers.

Nicoladis, Elena, and Giovanni Secco. 2000. The role of a child's productive vocabulary in the language choice of a bilingual family. First Language 20: 3-28. [CrossRef]

Paradis, Johanne, and Elena Nicoladis. 2007. The influence of dominance and sociolinguistic context on bilingual preschoolers' language choice. International Journal of Bilingual Education and Bilingualism 10: 277-97. [CrossRef]

Petersen, Jennifer. 1988. Word-internal code-switching constraints in a bilingual child's grammar. Linguistics 26: 479-93. [CrossRef]

Quay, Suzanne. 1995. The bilingual lexicon: Implications for studies of language choice. Journal of Child Language 22: 369-87. [CrossRef] [PubMed]

Quick, Antje Endesfelder, Elena Lieven, and Michael Tomasello. 2016. Mixed NPs in German-English and German-Russian bilingual children. In Cognitive Perspectives on Bilingualism. Trends in Applied Linguistics (TAL). Edited by Justyna A. Robinson and Monika Reif. Berlin: de Gruyter.

Quick, Antje Endesfelder, Ad Backus, and Elena Lieven. 2018a. Partially schematic constructions as engines of development: Evidence from German-English bilingual acquisition: Placing meaning, usage and mind at the core of contact-induced variation and change. In Cognitive Contact Linguistics. Placing Usage, Meaning and Mind at the Core of Contact-Induced Variation and Change. Edited by Eline Zenner, Ad Backus and Esme Winter-Froemel. Berlin: De Gruyter.

Quick, Antje Endesfelder, Elena Lieven, Malinda Carpenter, and Michael Tomasello. 2018b. Identifying partially-schematic units in the code-mixing of an English and German speaking child. Linguistic Approaches to Bilingualism 4: 477-501. [CrossRef]

Quick, Antje Endesfelder, Stefan Hartmann, Ad Backus, and Elena Lieven. 2019. Entrenchment and Productivity: The role of input in code-mixing of a German-English bilingual child. Applied Linguistics Review. [CrossRef]

Scott, Michael. 2004. WordSmith Tools, Version 4. Oxford: Oxford University Press.

Swain, Merrill. 1972. Bilingualism as a First Language. Unpublished dissertation, University of California, Irvine, CA, USA.

Szagun, Gisela, Barbara Stumper, Nina Sondag, and Melanie Franik. 2007. The acquisition of gender marking by young Germanspeaking children: Evidence for learning guided by phonological regularities. Journal of Child Language 34: 445-71. [CrossRef]

Tomasello, Michael. 2003. Constructing a Language: A Usage-Based Theory of Language Acquisition. Cambridge: Harvard University Press. Valian, Virginia. 1986. Syntactic categories in the speech of young children. Developmental Psychology 22: 562-79. [CrossRef] 
Vihman, Virve-Anelli. 2018. Language Interaction in Emergent Grammars: Morphology and Word Order in Bilingual Children's Code-Switching. Languages 3: 40. [CrossRef]

Walsh, Michael, Bernd Möbius, Travis Wade, and Hinrich Schŭtze. 2010. Multilevel Exemplar Theory. Cognitive Science 34: 537-82. [CrossRef]

Wasserscheidt, Philip. 2019. A usage-based approach to "language" in language contact. Applied Linguistics Review. [CrossRef] 